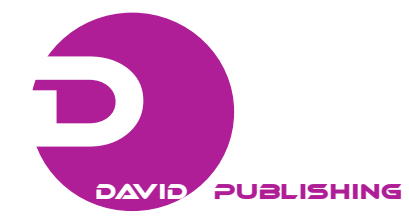

\title{
Expatriation as an Element of Diversity Management
}

\author{
Daniel H. Scheiblea
}

\begin{abstract}
The ongoing internationalization of companies goes hand in hand with an increase of international assignments. With it, knowledge is transferred and diverse teams emerge in the subsidiaries abroad. However, expatriation management and diversity management have been separated areas so far. Thus, the readiness to use expatriation as an integral element of an overall diversity strategy has been evaluated in an exploratory empirical study. For this purpose, semi-structured interviews have been conducted with both expatriates and HR (human resources) managers in six subsidiaries and the headquarters of an international mechanical engineering company. It was found that operative aspects of the expatriate management dominate the viewpoint of those involved. However, the findings also suggest that an implicit recognition of advantages that stem from the variety of individual employees exists. Willingness to systematically strengthen the exchange and learning process was detected. Based on these results, a new approach could be conceptualized and implemented. This provides various foci for further research.
\end{abstract}

\section{Keywords}

Expatriation, diversity management, human resource management, organizational learning

The expatriation of specialists and executives is an important instrument for international companies which strive to become global organizations. Reasons for the application of that instrument are various-from allocation or coordination concerns to the transfer of technological and managerial know-how or the implementation of strategies, up to organizational development and the aim to influence the corporate culture (Bolino 2007). In the traditional ethnocentric approach (Perlmutter 1969), the know-how transfer is a one-way flow of knowledge since expatriates are sent from headquarters to subsidiaries abroad. There they implement elements of the headquarters' base of knowledge by establishing changes in routines and processes and training colleagues. But in modern global organizations, market conditions and the imperative of efficiency require a high level of integration and strong ties between headquarters and subsidiaries (Bartlett and Ghoshal 2002). International assignments are manifold in nature and experiences gained in subsidiaries abroad will have an impact on former expatriates' behavior over the long run. Consequently, expatriation allows for a two-way flow of knowledge and for organization development on a mutual basis (Saka-Helmhout 2007).

When looking at organization development, based

aRhine-Waal University, Germany

\section{Correspondent Author:}

Daniel H. Scheible, Rhine-Waal University, Friedrich-Heinrich-Allee 25, 47475 Kamp-Lintfort, Germany

E-mail: daniel.scheible@hsrw.eu 
on the usage of individual knowledge and experiences of different people in various parts of the organization, managing diversity comes into focus (Cox 1994; Gardenswartz and Rowe 2008). The argument that heterogeneity can be managed in such a way that a competitive advantage can be created through learning and enhanced creativity (Ely and Thomas 2001) is widely accepted today-in organization development as well as in human resource management. In fact, this business case argument has widely replaced the former rationale of managing diversity for moral reasons such as avoiding discrimination (Lauring 2013).

Thus, a proper management of expatriation in terms of managing knowledge, opening new perspectives, and enriching teams can be deemed as a powerful instrument of diversity management. But astonishingly, a review of expatriation management literature as well as diversity management literature has shown that the question whether diversity management strategies of international companies are or can be supported by a structured management of expatriation processes has not been discussed yet.

Another interesting finding from the literature review was that research on expatriation management has indeed reflected different perspectives. Most often the expatriates themselves have been approached (Takeuchi, Shay, and Li 2008; Tung 1998). Other studies have adopted the organization's perspective (Harris and Brewster 1999; Harvey 1993) or more recently - the perspective of host country nationals who work with expatriates (Toh and DeNisi 2005; Vance, Vaiman, and Andersen 2009). But most of these studies have examined expatriation from only one of these perspectives. Only very few studies have systematically combined different perspectives (McEvoy and Buller 2013).

Based on these findings, an exploratory study has been designed aiming to examine expatriation management and its link to diversity policies in an international mechanical engineering company headquartered in Germany. Expatriation management and the potential of its foundation in a comprehensive diversity management approach have been evaluated from two perspectives: From current expatriates' point of view as well as from the human resource managers' perspective.

\section{METHODS}

\section{Background and Setting}

The examined organization is a mechanical engineering company with more than 100 years of history. Founded in Germany, the company internationalized early. Especially the past three decades have been characterized by a multitude of international acquisitions, joint-ventures, mergers, and demergers. Today, the company has around 22,000 employees worldwide. Besides Germany, main production plants are located in Brazil, China, France, India, Italy, UK, and USA.

According to its origin and history, the company can be described as highly engineering driven. Expatriates have been assigned whenever a technical demand occurred. Policies concerning the management of such international assignments have been in place, but a strategic approach of expatriate management in order to develop employees and the organization has been missing. Aspects of managing diversity have been addressed in order to meet legal requirements and corporate governance concerns, but no integrated diversity management approach has been developed. In this environment, the study on hand clearly has been explorative in nature. The readiness of expats and HR (human resources) managers to assume expatriation as a vehicle to productively managing the diversity within a multinational corporation has been explored. Results are supposed to be used for the development of a diversity management concept which strategically integrates existing elements—such as the expatriation policies. 
Table 1. Conducted Interviews

\begin{tabular}{|c|c|c|c|c|c|c|c|}
\hline \multirow[b]{2}{*}{ Cohort } & \multicolumn{7}{|c|}{ Number of respondents } \\
\hline & $\begin{array}{l}\text { Australian } \\
\text { subsidiary }\end{array}$ & $\begin{array}{l}\text { Chinese } \\
\text { subsidiary }\end{array}$ & $\begin{array}{l}\text { Czech } \\
\text { subsidiary }\end{array}$ & French subsidiary & British subsidiary & US subsidiary & Total \\
\hline Expatriates & 1 & 3 & 2 & 3 & 2 & 3 & 14 \\
\hline HR managers & 1 & 1 & 1 & 1 & 1 & 1 & 6 \\
\hline Total & 2 & 4 & 3 & 4 & 3 & 4 & 20 \\
\hline
\end{tabular}

\section{Data Collection and Analysis}

For this purpose, 14 expatriates and six HR managers of the company were selected for being interviewed. The interviewees were located in six subsidiaries of the company in Australia, China, Czech Republic, France, UK, and USA. Table 1 shows the distribution of interviewees by location. Thirteen expats held executive positions (vice presidents, department heads, and project leaders), one was a project member.

All interviews were conducted via telephone and recorded in an MP3 format. Gathering data by having a telephone conversation could be taken as an appropriate method since telephone is the preferred communication medium in the company's international administration. The duration of the 20 interviews varied between 27 and 48 minutes.

Two semi-structured interview guides were in use - one for the expatriates and another one for the HR managers. Fifty percent (50\%) of the main questions were identical in both guides. The questions covered aspects of the expatriation process (including preparation and repatriation) and its management, the role of expatriation in the light of cooperation and communication across the various sites, perception and appreciation of colleagues in the subsidiaries, and the interrelation between expatriation and human resource development. The interview guides were developed in three steps. The first versions of the two guides were developed based on a brainstorming with the Head of Human Resource Management, some document analyses, and a factory tour. After consultation with the Central Human Resource Management, the guides were revised. The second versions were tested in trial interviews, and with slight enhancements-converted into the final versions. Two interviewers were selected and trained. They conducted all the interviews within five weeks.

Afterwards, the interview records were transcribed, structured, and analyzed. Central statements and their interpretations were visualized in a spread sheet format, so that a comparative analysis could be performed. For the purpose of validating the findings, they were cross-checked by one of the HR managers working in the central HR department at the German headquarters.

\section{EMPIRICAL FINDINGS}

When asking expatriates as well as HR managers in the company the author examined, it became obvious that the importance of expatriation for international cooperation and its effect on organization development are recognized. Statements like becoming "a real team" through becoming acquainted with colleagues from the other sites of the company during a mid-term delegation (German expat in France) supported this view. Other interviewees emphasized effects like "sharing experiences", "passing on knowledge", and developing "a common international identity”. 
A few interviewees acknowledged that prejudices against the employees of the other sites exist. Especially employees in the international subsidiaries seem to have resentments against headquarters' employees. But several expats reported that such prejudices could be minimized during their sojourn abroad. Only one expat described a situation where misunderstandings based on cultural differences led to unfavorable circumstances. With it, an important assumption of diversity management can be regarded as verified: Forming a productive team that consists of people with diverse backgrounds requires facilitation (Gardenswartz and Rowe 2008). Apparently, expats can be seen as the facilitators in the examined organization. But if differences between the expat and other team members cause trouble, a third party is needed.

When having a look at experiences and opinions on what makes expatriation successful in the organization, both the HR managers and the expats had a quite "technical" view at the matter. Many issues of expatriate management were mentioned which have been discussed in scientific literature as well as practitioners' handbooks for several years now. Examples of these issues mentioned are the transparency of the selection process, the on-site support concerning accommodation, taxation, etc., and the need for long-term career planning at an early stage. Six expats asked for a more standardized process.

What appears interesting in the light of managing diversity are those issues which enable expats to take their role as facilitators of international cooperation and communication within the company. In this regard, language is a central theme for the respondents. Most of them expressed the opinion that improving the command of English as a lingua franca in all parts of the enterprise may help to form a unified global entity and a strong corporate culture. Additionally, they requested the provision of enhanced technical equipment (e.g., more standardized video conference systems for better connectivity between the sites). Obviously, for the majority of interviewees, standardization is the clue to effectiveness in international cooperation. Appreciation of differences among and within the different subunits of the organization was to a large extent out of the test persons' awareness. For example, it was mentioned in some interviews that international meetings are held in German or French sometimes-if all participants agree. However, this was not seen as a resource but as a "disturbance" of an all-embracing company communication in English.

On the other hand, the contributions of international assignments and structured expatriation programs were seen. One expatriate expressed his belief that a steady exchange of employees between the subsidiaries all over the world could lead to a full exploitation of existing competencies. Another expatriate reported that due to his special position of being an expat, changes in the subsidiary he was stationed at could be implemented more effectively. Both aspects show that advantages stemming from a variety of individual employees are implicitly recognized.

Among the HR managers, the belief that expatriation positively influences the organization's development is widely spread. All respondents out of this cohort wanted to foster international assignments and further develop instruments for doing this in a structured manner. The need for a kind of "expat database” was mentioned several times. One HR manager suggested to "send more employees from the (company)'s sites worldwide to (location of headquarters) so that these people get the chance to get to know the headquarters" (HR manager in the Czech Republic); in order to do so, he felt a need for a more open-minded corporate culture. Another hint that a lack of openness in the subsidiaries might exist, came from an expat in the UK who stated that "the different organizations don't want to lose their good people”. 


\section{DISCUSSION}

The shift in the underlying paradigms in managing diversity from fairness and legitimacy aspects toward organizational learning, based on the variety of individual traits, qualifications, and experiences, perfectly fits together with major reasons for the expatriation of employees within international organizations. In fact, in a passive role, expats directly increase the diversity of work teams in the subsidiaries; when facilitating the cooperation of employees across different sites, they actively contribute to managing diversity as seen in the study.

However, the findings of this empirical study suggest that neither international HR practitioners nor expatriates themselves see the expatriation practice in such a strategic context. This does not mean that the strategic dimension is not seen at all. A majority in both cohorts acknowledges the strategic contribution of expatriate management in terms of human resource development as well as organizational development, but rather under the premise of homogenization than diversification. The fact that the examined organization is a highly engineering driven company may support the assumption that an intense standardization will lead to optimal outcomes (Vernaik, Midgley, and Devinney 2005). Interestingly, expats and HR managers in most cases share this attitude. On the other hand, it is surprising that they of all employees who have experienced shifted contexts and a feeling of otherness focus so much on standardization instead of appreciating diversity and its benefits.

As the study has also revealed, frictions in operative expatriation management bind the scarce resources in the HR departments. As long as the growing complexity of HRM (human resource management) in an increasingly globalizing organization requires intensive learning and knowledge management efforts, the conceptualization of an expatriate policy, embedded in the overall diversity philosophy of a company, remains difficult. Most statements remain at the level "It would be nice to have”. But as long as the day-to-day problems in operations are overwhelming, nobody has room to further develop these ideas and take action.

Nevertheless, the findings of this exploratory study also show that in principle, the theoretical construct of expatriate management as an integral part of and contributor to a comprehensive diversity concept resonates with practitioners' views on their field of competence. Implicitly, the willingness to accept diversity as a resource for organizational learning and improved performance exists. It was uttered several times that learning from each other and sharing experiences can be beneficial. A concept that systematically uses this insight by showing the positive impact on developing superior solutions for customers, increasing self-esteem of all team members, etc. (Ely and Thomas 2001), should fall on fertile ground. However, overcoming traditional concepts of strengthening competitiveness by simply standardizing and unifying processes and behavior across all the locations of an organization seems to require intensive efforts at persuasion.

It has been the intention of this study to shed light on experiences with expatriation from two different perspectives - the expatriates' perspective and the HR managers' perspective. For a more complete picture, a third perspective could be contributory: the local employees' view. These employees (often called "host country nationals”) interact with the expats (Tarique, Schuler, and Gong 2006). Their estimation of the expatriates' contribution to constructively managing diversity in the international company could reveal additional issues since they represent a more "neutral" view-they are not directly involved in the expatriation processes.

Another limitation of this study can be seen in the fact that little experience with so called "third country nationals" (expats which are sent from one 
subsidiary to another) exist in the examined organization. This type of international assignments is widely assumed to increase in importance in international human resource management (PricewaterhouseCoopers [PwC] 2012; Reiche and Harzing 2015) since this approach of staffing corresponds with the best use of the human resources within an organization (Perlmutter 1969).

Finally, this has been an exploratory study to detect the potential of conceptualizing expatriate management as an integral part of a diversity management approach. Now, concepts and implementation strategies have to be developed. In the turbulent environments of global organizations, this is a challenging task which requires further research-research on how to implement these concepts as well as accompanying studies when launching them.

\section{CONCLUSIONS}

This study has revealed that using expatriation as a tool of diversity management not only has been neglected by the management literature so far but also by management practice. Although positive effects of expatriation on international cooperation and organization development are recognized by both expatriates and HR managers, those effects are not attributed to an increasing diversity of the organization. Thus, for successfully interlinking expatriation and diversity management, the development of fundamental concepts is required.

\section{References}

Bartlett, C. A. and S. Ghoshal. 2002. Managing Across Borders: The Transnational Solution. 2nd ed. Boston: Harvard Business School Press.

Bolino, M. C. 2007. "Expatriate Assignments and Intra-Organizational Career Success: Implications for Individuals and Organizations.” Journal of International Business Studies 38(5):819-835.
Cox, T. 1994. Cultural Diversity in Organizations: Theory, Research and Practice. San Francisco: Berrett-Koehler.

Ely, R. J. and D. A. Thomas. 2001. "Cultural Diversity at Work: The Effect of Diversity Perspectives on Work Group Processes and Outcomes." Administrative Science Quarterly 46(2):229-273.

Gardenswartz, L. and A. Rowe. 2008. Diverse Teams at Work: Capitalizing on the Power of Diversity. Alexandria: Society for Human Resource Management.

Harris, H. and C. Brewster. 1999. "The Coffee-Machine System: How International Selection Really Works.” International Journal of Human Resource Management 10(3):488-500.

Harvey, M. 1993. "Empirical Evidence of Recurring International Compensation Problems." Journal of International Business Studies 24(4):785-799.

Lauring, J. 2013. "International Diversity Management: Global Ideas and Local Responses." British Journal of Management 24(2):211-224.

McEvoy, G. M. and P. F. Buller. 2013. "Research for Practice: The Management of Expatriates.” Thunderbird International Business Review 55(2):213-226.

Perlmutter, H. V. 1969. "The Tortuous Evolution of the Multinational Corporation.” Columbia Journal of World Business 4(1):9-18.

PwC (PricewaterhouseCoopers). 2012. Talent Mobility 2020 and Beyond: The Future of Mobility in a Globally Connected World. London: PricewaterhouseCoopers.

Reiche, B. S. and A. W. Harzing. 2015. "International Assignments.” Pp. 145-190 in International Human Resource Management, 4th ed., edited by A. W. Harzing and A. H. Pinnington. London: Sage.

Saka-Helmhout, A. 2007. "Unravelling Learning Within Multinational Corporations.” British Journal of Management 18(3):294-310.

Takeuchi, R., J. P. Shay, and J. Li. 2008. “When Does Decision Autonomy Increase Expatriate Managers' Adjustment? An Empirical Test." Academy of Management Journal 51(1):45-60.

Tarique, I., R. Schuler, and Y. Gong. 2006. “A Model of Subsidiary Staffing Composition.” International Journal of Human Resource Management 17(2):207-224.

Toh, S. M. and A. DeNisi. 2005. "A Local Perspective on Expatriate Success.” Academy of Management Executive 19(1):132-145.

Tung, R. L. 1998. “American Expatriates Abroad: From Neophytes to Cosmopolitans.” Journal of World Business 33(2):125-144.

Vance, C. M., V. Vaiman, and T. Andersen. 2009. “The Vital Liaison Role of Host Country Nationals in MNC Knowledge Management.” Human Resource Management 
48(4):649-659.

Vernaik, S., D. F. Midgley, and T. M. Devinney. 2005. "Dual Paths to Performance: The Impact of Global Pressures on MNC Subsidiary Conduct and Performance.” Journal of International Business Studies 36(6):655-675.

\section{Bio}

Daniel H. Scheible, Ph.D., Professor of Business Administration and Intercultural Competence, Rhine-Waal University, Germany; research fields: strategic management, intercultural management, and diversity management. 